\title{
MicroRNAs as a Potential Target for Cancer Therapy
}

\author{
Abraham Nigussie Mekuria ${ }^{*}$, Abraham Degaga Abdi ${ }^{1}$ and Kirubel Minsamo Mishore ${ }^{2}$
}

${ }^{1}$ Department of Pharmacology, College of Health Sciences, Addis Ababa University, Addis Ababa, Ethiopia

${ }^{2}$ Department of Clinical Pharmacy, School of Pharmacy, College of Health and Medical Sciences, Haramaya University, Harar, Ethiopia

\begin{abstract}
MicroRNAs (miRNAs) are evolutionary conserved small non-coding RNAs that negatively regulate gene expression by several mechanisms. Deregulation in expression of miRNAs has been reported in the pathogenesis of cancer. Accordingly, studies identified down regulation in the expression of miRNAs having tumor suppressor role and up-regulation in the expression of oncogenic miRNAs in different types of cancer. In response to these observations currently there are ongoing efforts to develop safe and effective miRNA-based therapeutics in the hope of fighting against cancer. This paper aimed at reviewing the role of miRNAs in tumorigenesis, and strategies for therapeutic targeting of miRNAs in cancer.
\end{abstract}

Keywords: MicroRNA; Tumor; Novel target; Cancer therapy; Tumorigenesis; Tumor suppressor

\section{Introduction}

Cancer is a complex group of diseases characterized by the presence of cells with uncontrolled growth, and high proliferation capacity [1]. Based on insights from decades of research eight changes in cell physiology has been ascribed as hallmarks of cancer, including: sustaining proliferative signaling; insensitivity to antigrowth signals; evasion of apoptosis; limitless replicative potential; sustained angiogenesis; activating invasion and metastasis; as well as reprogramming of energy metabolism and evading immune destruction [2,3]. During development and in response to cellular milieu there might be switch- on or -off of expression of genes encoding proteins that regulate the above process and altered expression of the genes (tumor-suppressor genes and proto-oncogenes) arise from mutations, or expression deregulation in a multistep process resulting in cancer $[4,5]$. Moreover, recent studies have revealed the involvement of class of small non-coding singlestranded RNAs including microRNAs (miRNAs), and long non-coding RNAs in the development and progression of cancer [6,7]. This review aimed at appraising the most current literatures regarding the link between miRNAs and molecular pathogenesis of cancer and also the current approach in targeting miRNAs as cancer therapy.

\section{Literature Review}

\section{Overview of MicroRNAs}

MiRNAs, known to be a negative regulator of gene expression at posttranscriptional level, are small noncoding single-stranded RNAs of 18 to 24 nucleotides [6,8].

\section{Biogenesis and regulation}

As shown in Figure 1, biogenesis of miRNAs starts with formation of a primary transcript (pri-miRNA) by RNA polymerase II, or sometimes by RNA polymerase III [9]. Pri-miRNA has a stem-loop structure, is capped at the $5^{\prime}$-end and has a 3 '-poly (A) tail [10]. Then, drosha complex (microprocessor complex), process pri-miRNAs into hairpin-structured precursor miRNAs (pre-miRNAs) inside the nucleus [11]. Furthermore, the pre-miRNAs are transported into the cytoplasm by Exportin- 5 (XPO5) along with Ran-GTP [12]. Once it reaches in the cytoplasm, the pre-miRNA will be digested into a mature duplex miRNA by a Dicer (RNase III) [13]. In this regard, biogenesis of miRNAs has been known to be regulated at different levels, including at level of miRNA transcription $[13,14]$, processing in to mature duple miRNA (Drosha, Dicer and their accessory proteins) [15-20].

On the other hand, so as to interfere in the expression of variety of genes, one strand of the miRNA duplex will be loaded onto the miRNAinduced silencing complex (RISC) [14], which then regulates the translation of complementary messenger RNA (mRNA) [15]. As studies identified, interaction of miRISC to mRNA achieved by recognizing its complementary sequences in the 3'untranslated region (UTR) of their target mRNAs through seed region, typically positions 2-7 in the miRNA [14,15]. As shown in Figure 2, miRNAs negatively regulate gene expression through different mechanisms including, inhibition of translation initiation and post-initiation and induction of mRNA destabilization and decay [11,21-28]. Meanwhile strict complementarity is not obligatory for regulation, one miRNA may target a number of mRNAs and subsequent aberrant miRNA expression may affect a multitude of transcripts, which have remarkable effect on cancer-related signaling pathways [11].

\section{Aberrant Expression in Cancer}

The initial remark that provided a possible link between miRNA and carcinogenesis was the loss-of-function mutations phenotype of lin-4 and let-7 in C. elegans. Accordingly, mutants of lin-4 and let-7 resulted in extra cell divisions during the adult stage, beyond larval stages, linking in the control of cell differentiation and proliferation [21,22]. However, the most direct evidence linking miRNAs to cancer came from the discovery of deletions of the miR-15a/16-1 cluster in chromosome 13q14 in chronic lymphocytic leukemia cells by Calin [29]. According to this study, miR-15a/16-1 shown to regulate BCL2, signifying a mechanism by which CLL could be caused due to loss of mir-15a and mir-16-1. Since then, thousands of tumor miRNA expression profiling studies has generated an expansive list of miRNAs (Tables 1 and 2) [30-32]. In this

*Corresponding author: Abraham Nigussie Mekuria, PHD student in Pharmacology, Department of Pharmacology, College of Health Sciences, Addis Ababa University, Addis Ababa, Ethiopia, Tel: +251-115-152753; E-mail: abrishn@yahoo.com

Received May 16, 2018; Accepted June 19, 2018; Published June 21, 2018

Citation: Mekuria AN, Abdi AD, Mishore KM (2018) MicroRNAs as a Potential Target for Cancer Therapy. J Cancer Sci Ther 10: 152-161. doi: 10.4172/19485956.1000535

Copyright: () 2018 Mekuria AN, et al. This is an open-access article distributed under the terms of the Creative Commons Attribution License, which permits unrestricted use, distribution, and reproduction in any medium, provided the original author and source are credited. 
Citation: Mekuria AN, Abdi AD, Mishore KM (2018) MicroRNAs as a Potential Target for Cancer Therapy. J Cancer Sci Ther 10: 152-161. doi: $10.4172 / 1948-5956.1000535$

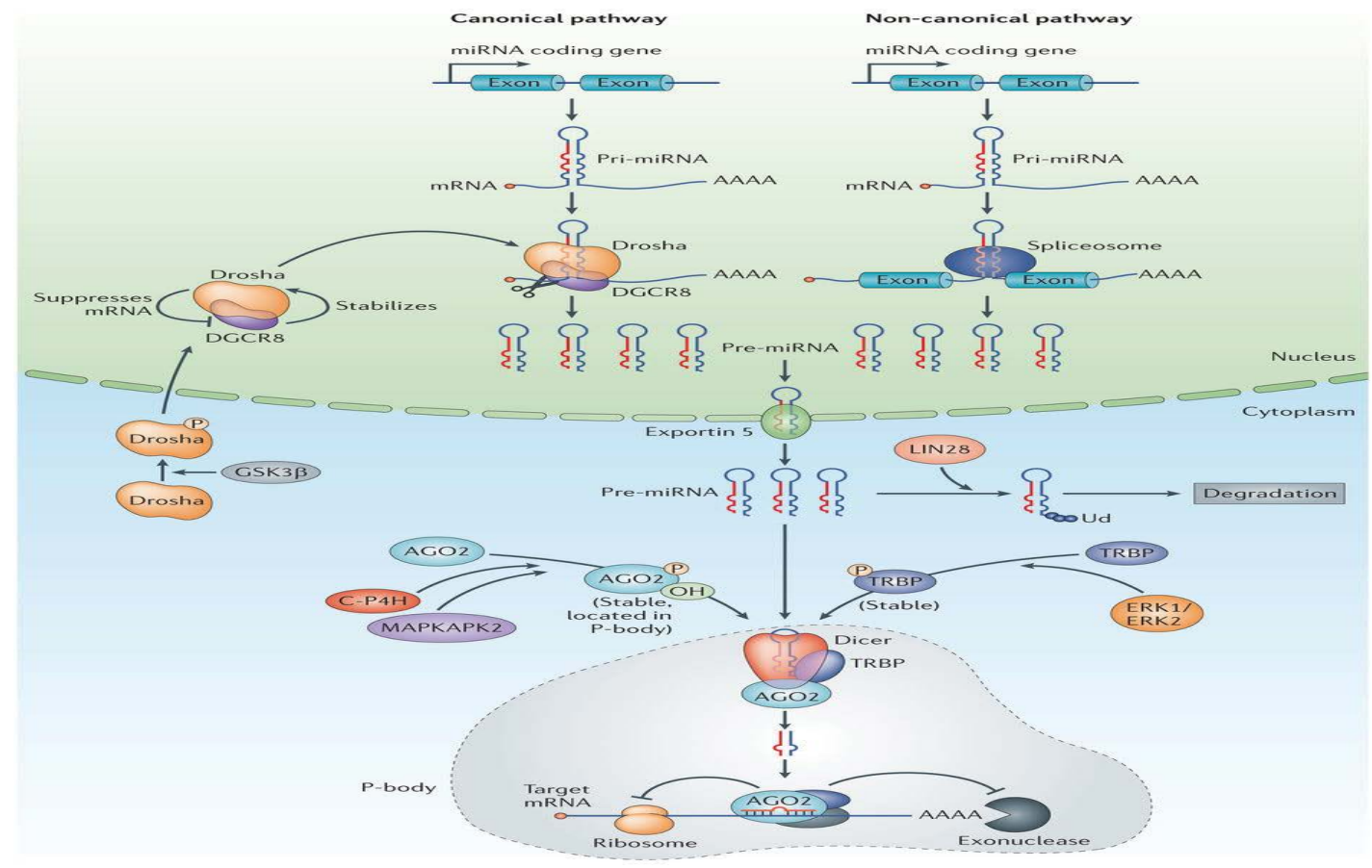

Figure 1: MicroRNA biogenesis pathways [11].

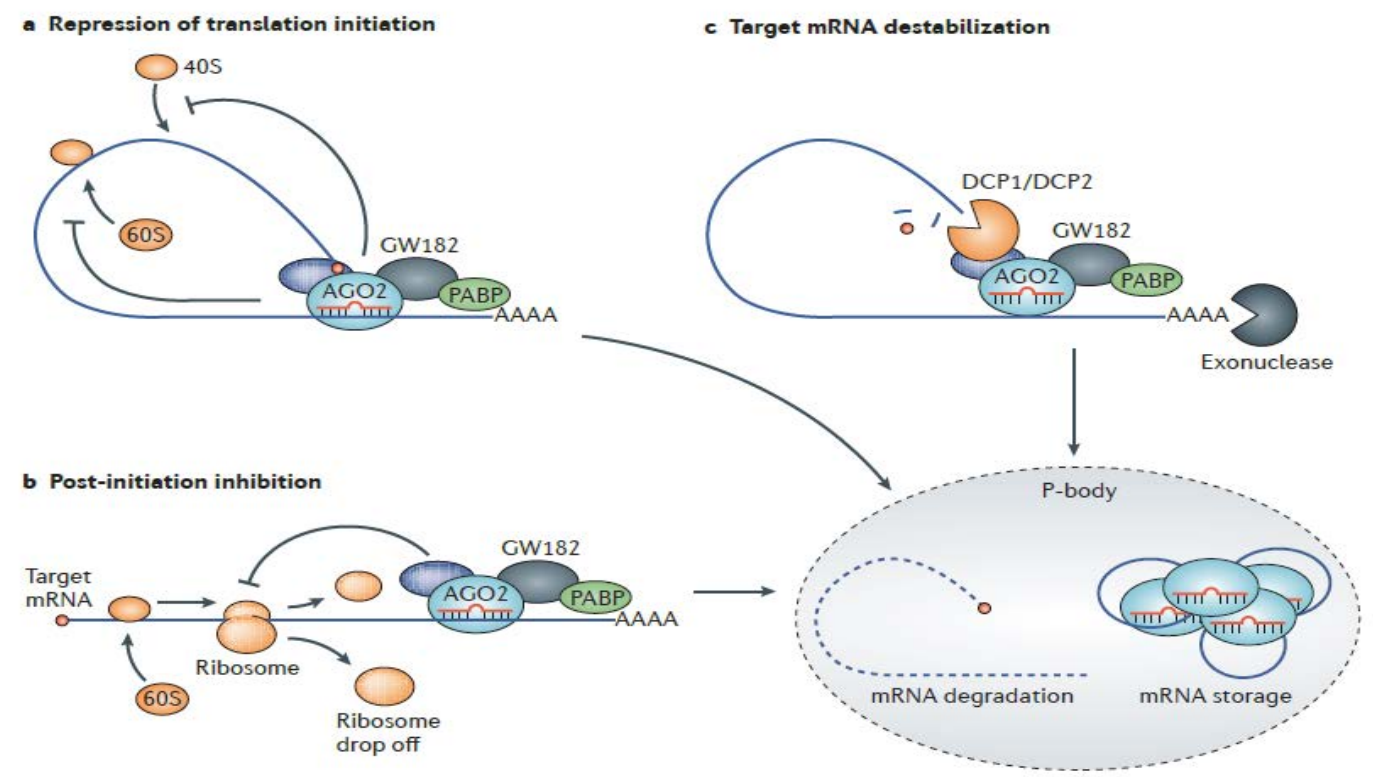

Figure 2: miRNA function: potential mechanisms includes, (a) Repression of translation initiation. MicroRNA (miRNA)-mediated silencing complexes (miRISCs) inhibit the initiation of translation by affecting eukaryotic translation initiation factor $4 \mathrm{~F}$ (elF4F) cap recognition, $40 \mathrm{~S}$ small ribosomal subunit recruitment and/or by inhibiting the incorporation of the $60 \mathrm{~S}$ subunit and the formation of the $80 \mathrm{~S}$ ribosomal complex. Some of the target mRNAs bound by the miRISC are transported into processing bodies (P-bodies) for storage and may re-enter the translation phase when induced by exogenous signals such as stress. (b) Post-initiation translational repression. miRISCs may inhibit the elongation of ribosomes, causing them to drop off the mRNAs and/or facilitate the degradation of newly synthesized peptides. (c) Destabilization of target mRNAs. Binding of miRISCs to target mRNAs may recruit RNA decapping and/or deadenylating enzymes that lead to mRNA destabilization. P-bodies are the key cellular organelles for the degradation and storage of targeted mRNAs. AGO2, Argonaute 2; DCP1, mRNA-decapping enzyme 1; PABP, poly(A)-binding protein [11]. 
Citation: Mekuria AN, Abdi AD, Mishore KM (2018) MicroRNAs as a Potential Target for Cancer Therapy. J Cancer Sci Ther 10: 152-161. doi: 10.4172/1948-5956.1000535

\begin{tabular}{|c|c|c|}
\hline MicroRNA & Cancer type & Function \\
\hline miR-29b & AML & Represses Sp1 which resulted in c-KIT inhibition \\
\hline miR-34b/c & Lung cancer & A positive feedback between p53 and miR-34 mediates tumor suppression in human lung cancer \\
\hline miR-126 & Breast, lung, colon cancers & Plays a critical tumor-suppressor role in tumor initiation and metastasis \\
\hline miR-150 & & AML A critical tumor-suppressor gatekeeper in AML by targeting FLT3 and Myb \\
\hline miR-155 & Breast cancer & Downregulates RAD51 and sensitizes cancer cells to irradiation \\
\hline miR-181a/b & AML & Their increased expression is associated with good prognosis and hinders tumor cell growth \\
\hline miR-375 & Breast cancer & Forced expression re-sensitizes cells to Tamoxifen treatment \\
\hline miR-494 & Lung cancer & Regulated by ERK1/2 it modulates proliferation and apoptosis response \\
\hline miR-495 & AML, gastric cancer & Specifically, down-regulated in MLL-rearranged, shown to block migration and invasion \\
\hline$m i R-551 a$ & Gastric cancer & Forced expression leads to a block in migration and invasion \\
\hline Let-7 & Lung cancer & Inhibits the expression of oncogenes involved in cell proliferation, such as Myc, RAS, and HMGA2 \\
\hline MiR-200 & Lung cancer & Inducement of epithelial-mesenchymal transition \\
\hline
\end{tabular}

Table 1: Examples of tumor-suppressor miRNAs [30,31].

\begin{tabular}{|c|c|c|}
\hline MicroRNA & Cancer type & Function \\
\hline miR-9 & AML & Specifically overexpressed in MLL-rearranged AML and promotes leukemia progression \\
\hline miR-17-92 & AML & Up-regulated in MLL-rearranged AML and targets p21 and RASSF2 \\
\hline miR-21 & Breast & Overexpression of miR-21 contributes to proliferation and metastasis \\
\hline miR-27a & Lung & Promotes proliferation in NSCLC cells \\
\hline miR-30a/c & RCC & Downregulation leads to increased expression of HIF2a \\
\hline miR-126 & AML & Up-regulated in core-binding factor (CBF) leukemia \\
\hline miR-181a/b & Breast, liver, colon & Promoted EMT, migration and invasion \\
\hline miR-196a & Gastric & Upregulated in MLL-rearranged AML and targets Fas \\
\hline miR-196b & AML & Marker of circulating tumor cells \\
\hline miR-421 & Gastric & Promote the progression of NSCLCs, in part by downregulating SOCS1, SOCS6, and PTEN \\
\hline miR-155 & Lung & Promotes cell migration and suppresses apoptosis by targeting TIMP3 and PTEN \\
\hline miR-221/222 & Lung &
\end{tabular}

Table 2: Examples of oncogenic miRNAs [30,32].

regard, miRNAs that has been up-regulated and support oncogenesis in some cancers are called "oncomiRs," while, miRNAs that has been known to be down-regulated that act as tumor suppressors are named as "tumor suppressor miRs".

\section{Possible mechanisms of deregulated expression}

A tumor cell has been known to have a deregulated expression of miRNAs $[33,34]$. The underling mechanisms include chromosomal abnormalities, changes in transcriptional and epigenetic regulation and also alteration in the miRNA biogenesis pathways (Figure 3) [29,34,35].

Alterations in genomic miRNA copy numbers and location changes: Abnormal miRNA expressions in tumor cells compared with normal cells are often attributed to alterations in genomic miRNA copy numbers and gene locations, i.e. amplification, deletion or translocation $[5,34]$. For instance, the loss of miR-15a/16-1 cluster gene at chromosome 13q14 was due to miRNA gene location change, which is frequently observed in B-cell chronic lymphocytic leukemia patients [29]. In addition, in lung cancer, the $5 \mathrm{q} 33$ region harboring miR-143 and miR-145 is often deleted, resulting in decreased expression of both miRNAs [36]. On the other hand, amplification of miR-17-92 group gene has been observed in B-cell lymphomas and lung cancers, and translocation of this gene was also observed in T-cell acute lymphoblastic leukemia, leading to overexpression of these miRNAs in these malignancies [37-39].

Moreover, Zhang [40] reported high frequency of DNA copy number alterations in miRNA loci based on high-resolution arraybased genomic analysis of 227 specimens obtained from human ovarian cancer, breast cancer and melanoma. Besides, other genome-wide investigations revealed that many miRNA genes are located in cancerassociated genomic regions [41]. Generally, these discoveries suggested that, abnormal miRNA expression in cancer cells could arise from amplification or deletion of specific genomic regions encompassing miRNA genes.

Alteration in transcriptional regulation: As mentioned above, expression of miRNA has been known to be controlled by transcription factors [14]. It is, therefore, alteration in the activity or expression of key transcription factors, including c-Myc and p53 will result in deregulated expression of miRNA in tumor [42-46]. For instance, a study done by O'Donnell [43] showed that over expression of c-Myc, known to be commonly up-regulated in different types of malignancies, promote expression of oncogenic miR-17-92 cluster via interaction with E-box elements in miR-17-92 promoter region so as to up-regulate tumor cell proliferation. In accordance with its oncogenic role, c-Myc also represses transcriptional activity of tumor suppressive miRNAs such as mir-15a, miR-26, miR-29, mir-30 and let-7 families [44]. Furthermore, a study done by Wang [42] showed the reciprocal regulation of c-Myc and tumor suppressor miR-122 in hepatocellular cancer. Accordingly, disruption of this feedback loop between miR-122 and c-Myc is essential for hepatocellular carcinoma (HCC) development.

Moreover, other studies also demonstrated that, p53 can induce the expression of miRNAs like miR-34a to trigger apoptosis through direct binding to the promoter of mir-34a gene. Consecutively, miR34a promotes $\mathrm{p} 53$ expression by targeting SIRT1, a negative regulator of p53 via deacetylation $[47,48]$. Further studies also showed that p53 performs its function through regulating the expression of a range of miRNAs, such as miR-605, miR-1246, and miR-107 [49-51]. It is; 


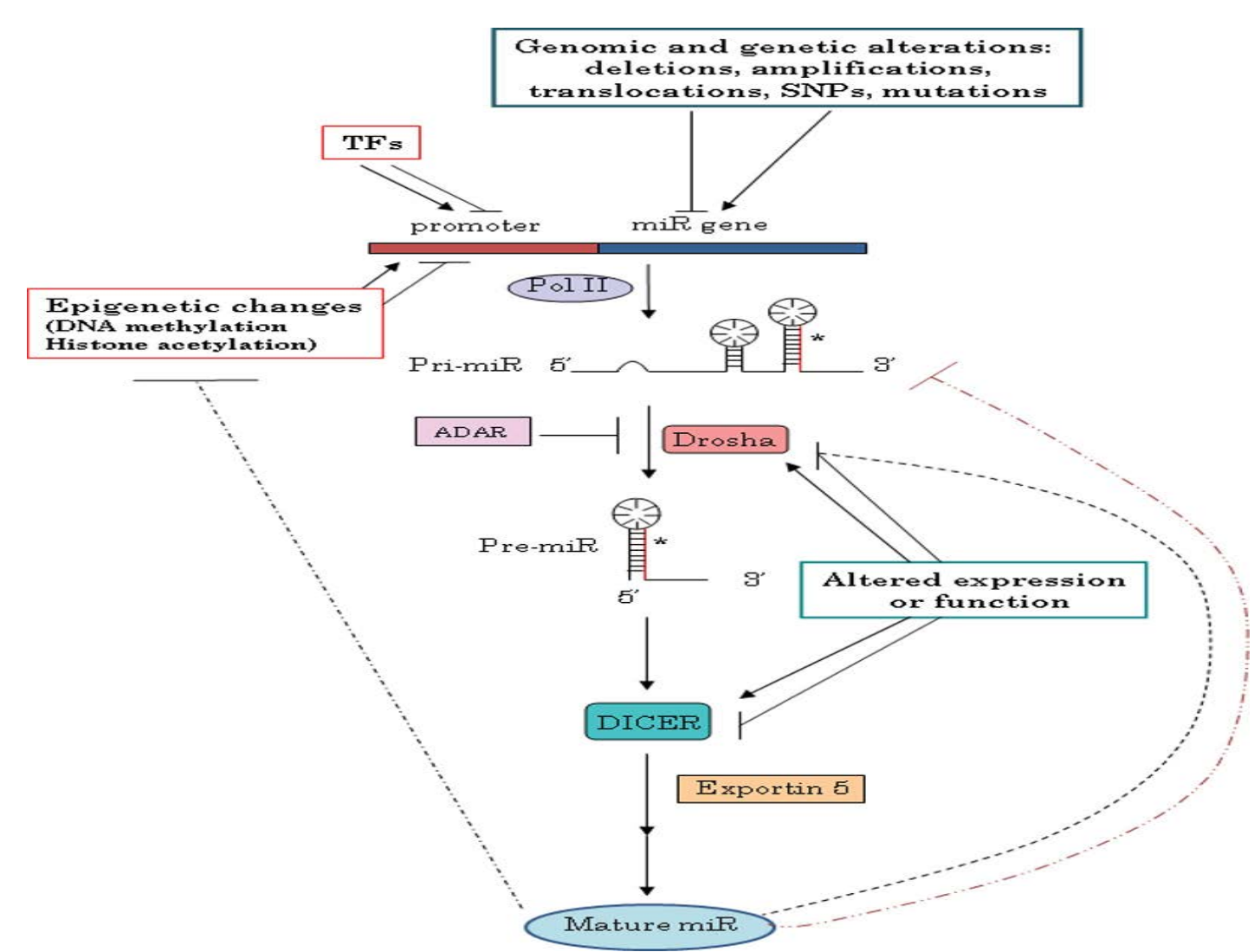

Figure 3: MicroRNA expression regulation and cancer. These mechanisms include chromosomal abnormalities, changes in transcriptional and epigenetic regulation and also defects in the miRNA biogenesis machinery [34].

therefore, miRNA expression is finely tuned by transcription factors that maintain its normal transcription, and dysregulation in this control might leads to tumorigenesis.

Epigenetic alterations: The epigenetic change is an eminent feature in cancer development and progression, including global genomic DNA hypomethylation, aberrant DNA hypermethylation of tumor suppressor genes and disruption of the histone modification patterns [52]. For example, a study done by Fazi [53] reported silencing of miR-223 expression by AML1/ETO, a most common AMLassociated fusion protein. Furthermore, Lujambio [54] reported CpG methylation associated silencing of miR-148a and miR-34b/c group due to hypermethylation in tumor. In the same study, restoration of these miRNAs in tumor has been associated with inhibition of motility, tumor growth and metastasis in vivo [54]. By the same token, decreased expressions of miR-9-1, miR-124a and miR-145-5p were attributed to DNA hypermethylation in breast, lung and colon carcinomas, respectively [52]. To this end, these evidences highlighted the role of epigenetic regulation in miRNA expression during tumorigenesis.

Alteration in the biogenesis pathway: Several studies reported abnormal expression and subcellular localization of miRNA processing enzymes/proteins in to mature duple miRNA including Drosha, Dicer and TARBP1, exportin5, TARBP2, correlation with tumor progression and poor prognosis [55-62].

\section{Role in Tumor Development and Progression}

It is believed that alteration in the expression of miRNAs could affect one or several of the cancer hallmarks for tumor initiation and progression. Depending on their target genes, miRNA could act as either oncogene or tumor suppressor under certain circumstances $[33,35]$.

\section{Unlimited proliferation}

The E2F proteins are known to be critical regulators of cell proliferation in a cell-cycle-dependent manner [62]. The E2F member E2F1 induces target gene transcription during the G1 to $S$ transition and is defined as a tumor suppressor because the E2F1-deficient mice developed a wide variety of cancers [63]. Among several studies that revealed E2F as target of miRNAs, a study done by O'Donnell [43] was considered as a pioneering study. This study revealed that miR-17-92 inhibits E2F1 translation after being activated by the transcription factor c-Myc. In support with this notion, forced expression of miR-1792 cluster shown to promote increased proliferation and undifferentiated phenotype of normal lung cells [64]. Moreover, miR17-92 cluster was also found to regulate E2F2 and E2F3 translation, and the E2F transcription factors can in turn induce the expression of the miR-17-92 cluster $[63,65]$. These studies signify the important role of miR-1792 in proliferation and survival.

Furthermore, cell-cycle progression depends on different cyclins, Cdks and their inhibitors, which are widely regulated by miRNAs [6671]. In this regard, Gillies and Lorimer [66] reported that Cdk inhibitor p27Kip1 as a target for miR-221/222 and revealed the role of these mRNAs in promoting the aggressive growth of human glioblastoma. 
Other studies done by Galardi [67] and Visone [68] also confirmed the above-mentioned role of miR-221/222 using human prostate and thyroid papillary carcinoma cell lines, respectively. Similarly, other G1/S transition regulators like p21CIP1 and p16INK4a are also regulated by miRNAs such as miR-663, miR-302 family and miR-24 [69,70]. To this end, miRNAs have a hand in in cell proliferation, not only through targeting cell-cycle components but also by far regulating multiple signaling pathways. Such as, miR-486, significantly down-regulated in non-small-cell lung cancer, was found to affect cell proliferation and migration through insulin like growth receptor (IGFR) and PI3K pathways by targeting IGF1, IGF1R and p85 $\alpha$ [71,72].

\section{Evasion of apoptosis}

Resisting apoptosis is another significant hallmark of tumor progression, which is also controlled by miRNAs [73,74]. Tumor cells develop a variety of strategies so as to circumvent apoptosis; however, the loss of p53 tumor suppressor function is most important. Other ways to escape apoptosis include upregulation of anti-apoptotic regulators, down-regulation of pro-apoptotic factors and inhibition of death pathway induced by extrinsic ligands. The components involved in pro-apoptotic and anti-apoptosis pathways were known to be broadly inhibited or activated by miRNAs [75].

For instance, studies done by Fornari [76] and Burns [77] showed that, miR-122 enhances p53 activity through targeting cyclin G1 and cytoplasmic poly (A) element-binding protein that improves tumor sensitivity to the drug doxorubicin, founding a root headed for the development of combined chemo and miRNA-based therapy for HCC. Similarly, alteration of other p53-regulated miRNAs also confers cancer cells resistant to apoptosis. Such as, miR-17-92 cluster is a novel target for p53-mediated transcriptional repression under hypoxia. In support of this, studies identified that down-regulation of miR-17-92 expression sensitizes cells to hypoxia-induced apoptosis, whereas its overexpression inhibits apoptosis [78,79]. It is therefore, p53 and its regulated miRNAs form a network to elaborately determine cell fate under normal conditions.

Furthermore, anti-apoptotic regulators $\{\mathrm{B}$-cell CLL/lymphoma 2 (Bcl-2) and $\mathrm{Bcl} 2$-like $1 \mathrm{~L}$ isoform $(\mathrm{Bcl}-\mathrm{xL})\}$ and proapoptotic factors (Bax, Bim and Puma) are known to be potential targets of some miRNAs having key role in cell death [80-84]. For instance, miR-15a and miR16-1 are significantly down-regulated in chronic lymphocytic leukemia and their expression inversely correlates with Bcl-2 expression. Subsequent study demonstrated that, these two miRNAs repress $\mathrm{Bcl}-2$ expression and induce apoptosis. Moreover, Bcl-2 has been identified to be regulated by other miRNAs, such as miR-204, miR-148a and miR365 [80-82]. On the other hand, a study done using ovarian cancer cell lines reported that efficient induction of apoptosis when miR-491-5p expression was restored through inhibition of $\mathrm{Bcl}-\mathrm{xL}$ expression and inducing Bim accumulation in its activated form [83]. According to the same study, dephosphorylated form of Bim accumulation was through targeting of epidermal growth factor receptor (EGFR) by miR-491$5 p$ and ensuing inhibition of downstream AKT and MAPK signaling cascade [83].

On the other hand, miRNAs have been also involved in controlling apoptosis via regulation of extrinsic apoptotic pathway [84]. For instance, a study done by Mo [85] showed that miR-196B directly repressed one of the element of the extrinsic apoptotic cascade first apoptosis signal (FAS) expression in colorectal cancer cells, however, FAS expression was constitutively elevated in normal human colorectal tissues. In the study, anti-miR-196B resulted in up-regulation of FAS expression and improved apoptosis in colorectal cancer cell lines. The authors concluded that over-expression of miR-196B modifies apoptosis in colorectal cancer cells in part by repressing FAS expression.

\section{Invasion and Metastasis}

Even if the mechanisms are not entirely understood, some miRNAs have been identified as important effectors in cell migration and metastatic pathways [86-89]. For instance, miR-10b that is transcriptionally controlled by an epithelial-mesenchymal transition (EMT) facilitator, Twist 1 has been identified as a potential promoter of metastasis. Accordingly, elevated expression of miR-10b in metastatic breast tumor brings cell migration and metastasis through targeting of HOXD9 and subsequent upregulation of a pro-metastatic gene RHOC, which is suppressed by HOXD9 [87]. Conversely, miR-221, being one of the significant miRNAs in tumor progression and metastasis, is downregulated in metastatic tissue compared with their primary carcinomas. Moreover, it has been suggested as a prognostic marker for high-risk prostate cancer [88]. In addition, in a recent study, it has been shown that miR-34a, which is transcriptionally controlled by $\mathrm{p} 53$, directly targets CD44 and represses its expression. It has been reported that miR-34a is down-regulated in CD44+ cells isolated from xenografts and primary tumors, leading to an increased metastatic potential [90]. Similarly, miR-373 and miR-520c, members of the same miRNA family, have been shown to suppress CD44 through preventing its translation [91]. Moreover, miR-708 has been found to be down-regulated in CD44+ cells extracted from xenografts, and CD44 has been validated as a direct target for miR-708 [89]. Furthermore, recent reports revealed that several miRNAs including let7c, miR-16, miR-21, miR-34a, miR100, miR-126, miR-145, miR-200, miR-205, miR-218 and miR-335 have been identified as potential markers for the metastatic status of distinct cancers $[86,92]$.

\section{Sustained Angiogenesis}

According to studies, miRNAs have been found to regulate various stages of angiogenesis [93-100]. For instance, miR-210 is the most consistently and significantly induced miRNA during hypoxia [94]. Accordingly, some studies demonstrated that miR-210 overexpression in normoxic human umbilical vein endothelial cells stimulates the formation of capillary-like structures and Vascular endothelial growth factor (VEGF)-dependent cell migration [95,96]. However, miR-210 inhibition using anti-miRNA transfection prevented these processes [95]. In this regard, miR-210 induced promotion of angiogenesis known to be mediated through down regulation of the receptor tyrosine kinase ligand ephrin-A3 (an antiangiogenic factor) expression [95], and also down regulation of VEGF and VEGF receptor-2 expression [97]. Besides, miR-424 has been shown to promote angiogenesis in vitro and in vivo during hypoxia in endothelial cells via cullin 2 , a scaffold protein critical to the assembly of the ubiquitin ligase system that resulted in stabilized hypoxia-inducible factor (HIF)-1 $\alpha$ and enhanced expression of VEGF [98]. On the other hand, miR-20b and miR-519c have been recognized as a negative regulator of angiogenesis by targeting VEGF and/or HIF1a $[99,100]$.

\section{Targeting Micro-RNAs for Cancer Therapy \\ Inactivating oncogenic miRNAs}

This strategy aimed at inactivating oncogenic miRNAs that are highly expressed in tumor cells. They are targeted for inhibition with complementary sequences that impair the processing of endogenous miRNA by RISC. Potential therapeutic candidates include antisense 
Citation: Mekuria AN, Abdi AD, Mishore KM (2018) MicroRNAs as a Potential Target for Cancer Therapy. J Cancer Sci Ther 10: 152-161. doi: 10.4172/1948-5956.1000535

anti-miR oligonucleotides (AMOs), miRNA sponges, and small molecule inhibitors [101,102].

\section{Anti-miRNA oligonucleotides}

AMOs are chemically modified anti-sense oligonucleotides (ASOs) that are designed as complementary to a selected oncogenic miRNA to be inhibited [103]. In this regard, they could be considered as competitive inhibitors of oncogenic miRNAs by forming duplex with mature miRNA and preventing its interaction with its target mRNAs (Figure 4) [104]. Moreover, RNAse-H-mediated degradation of target miRNA gene will be resulted once ASO-miRNA duplex formed via Watson Crick binding [105]. To improve affinity to target RNA, cellular uptake and resistance to nuclease numerous modification has been done to AMOs [106]. For instance, resistance to nuclease and affinity to target RNA has been improved by sugar modifications, including 2'-O-methyl, 2'-methoxyethyl, 2'-fluoro, or bicyclic locked nucleic acid (LNA) [107]. Whereas, substitution of phosphodiester backbone linkages with phosphorothioate, as well as, using peptide nucleic acid or morpholino oligomers, has been shown to enhance their pharmacokinetic properties and stability [108-110]. According to studies, miR-21 has been shown to be overexpressed in glioblastomas, and their knockdown has been associated with improved apoptotic activity [111]. In support of this, a study done by Griveau [112] showed that silencing of miR-21 by LNA-lipid nanocapsule complexes sensitize human glioblastoma cells to radiation-induced cell death.

\section{MicroRNA sponges}

As a DNA construct(s), they contain artificially designed miRNAbinding sites in the 3'-UTR of a nontoxic gene and they serve as competitive inhibitors by binding to complementary oncogenic miRNAs, thereby 'soaking up' existing oncogenic miRNAs pool (Figure 4) [113]. According to few studies, they have shown to inhibit target miRNAs in vitro and in vivo [114]. However, their therapeutic value has been limited due to issues related to their delivery target cancer cells [102].
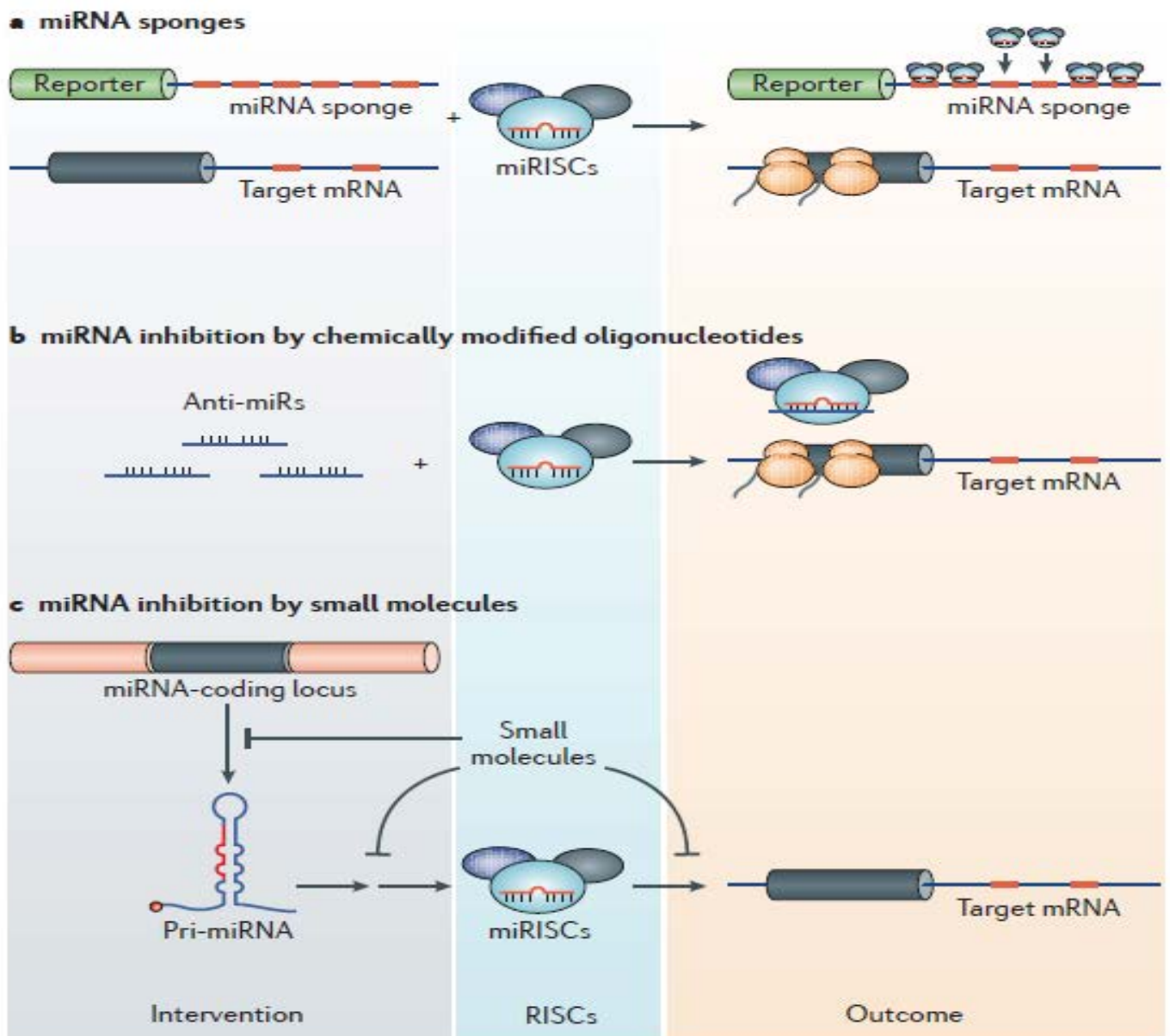

Figure 4: miRNA inhibition strategies. (a) MicroRNA (miRNA) sponges. Multiple miRNA-binding sites are inserted downstream of a reporter gene. When delivered into cells, the binding sites serve as decoys for the targeted miRNA, thereby reversing the suppression of endogenous target genes. (b) Chemically modified miRNA-targeting antisense oligonucleotides (anti-miRs) are designed to be fully complementary to the target miRNA and bind with high affinity (high melting temperature; $T_{m}$ ). When delivered into cells, the anti-miRs bind to the target miRNA, relieving inhibition of the endogenous target genes. Many anti-miRs also induce degradation of targeted miRNAs. (c) Small-molecule inhibitors can target at least three steps of miRNA assembly and function. First, small molecules can interfere with the transcription of primary miRNAs (pri-miRNAs). This inhibition could be at multiple steps, including transcription initiation, elongation and intron splicing Second, small molecules can inhibit pri-miRNA processing by Dicer and loading into Argonaute 2 (AGO2) to form an active RNA-induced silencing complex (RISC). Third, interactions between RISC and target mRNA can be perturbed by small molecules. All of these mechanisms would lead to the loss of repression of a target mRNA by miRs. miRISC, miRNA-induced silencing complex [11]. 


\section{Small molecule inhibitors}

As shown in Figure 4, they have been designed to target oncogenic miRNA. They can interfere with primary RNA transcription, or premiRNA processes by DICER and RISC, or RISC and target mRNA interaction [101]. One limitation of using such inhibitors could be non-specific targeting of miRNA and off target consequences [115]. The first specific small molecule inhibitor of specific miRNA (SMIR) to be discovered was an azobenzene that shown to inhibit miR-21 by inhibiting miR-21 precursor [116]. Further studies have focused on SMIRs to inhibit miR-122, which plays an important role in HCV and have identified several compounds which inhibit miR-122 [117] for further testing.

\section{Restoring Tumor Suppressor miRNA Expression}

Micro-RNA replacement therapy can be made by two different strategies: using viral vector-based gene restoration or by miRNA mimics [118]

\section{MicroRNA Mimics}

Based on studies, ectopic expression of synthetic miRNAs mimics with tumor suppressor role in have been shown to induce apoptosis and block proliferation in cancer [119]. For example, restoration of miR-15-a and miR-29 induced cell death in acute myeloid leukemia (AML) and prostate cell lines, respectively [120,121]. Further studies reported that, intra-tumoral injection of miR-29 mimics shown to decrease tumorigenicity in human liver and AML xenograft murine models [122,123]. Moreover, intranasal administration of let-7 in a K-ras mutant mouse effectively restrained the growth of the tumors by repression of proliferation and cell cycle pathways $[124,125]$.

Furthermore, a study done by Trang [126] using Kras-activated autochthonous mouse model of non-small cell lung cancer (NSCLC), systemic delivery of miR-34a in complex with novel neutral lipid emulsion has been shown rise the level of this tumor suppressor miRNA and has been associated with a significant decrease in tumor burden. Besides in other studies, miR-34a has shown to inhibit tumor growth in different preclinical studies using mouse model of cancer, including HCC and prostate cancer [127,128].

Owing to its promising anti-tumor activities in preclinical studies, phase 1 clinical trial was initiated by the biopharmaceutical company Mirna Therapeutics in 2013. The study has been started using MRX34 (a lipid-formulated miR-34 mimic) in order to evaluate its safety in patients with HCC or other selected solid tumors or hematologic malignancies but unfortunately, the clinical study was halted in 2016 because of multiple immune related severe adverse events (SAEs) [NCT01829971].

\section{Adenovirus Associated Vectors (AAV)}

Another strategy to enhance the expression of a tumor suppressor miRNA in cancer utilizes adenovirus associated vectors (AAV) [129]. These vectors do not integrate into the genome and are eliminated efficiently with minimal toxicity, as shown in phase I and phase II clinical trials in about 200 patients [101]. Another advantage of AAV vectors is the efficient transduction of target cells [130]. Moreover, Kota [131] revealed that, miR-26 role as tumor suppressor miRs in human HCC. Similarly, in a study done by Chen [132] tumor-specific expression of microRNA-26a has shown to suppress human HCC growth through cyclin-dependent and -independent mechanisms. In addition, AAVmediated systematic administration of miR-26a has shown to inhibit tumor growth in a spontaneous murine liver cancer model, in a study conducted by Kota [131]. This way of systemic administration could be worthwhile for HCC treatment, since it is readily targeted by both viral and non-viral gene and small molecule delivery systems. But, the efficacy of this system for other types of tumors and in different locations is not yet clearly known [133].

\section{Discussion and Conclusion}

Over the past two decades several studies have proven the significance of miRNAs in normal cellular homeostasis and in the initiation and progression of cancer. In this regard, the novel approach of cancer treatment using miRNAs is particularly inspiring in showing the importance of basic research, which in this case, has proven to be relevant in the development of new treatments for cancer. However, miRNA-based therapeutics are still in their infancy stage and there are many important challenges that the scientific community still needs to address. Efficient delivery of miRNAs faces various barriers, such as delivery-associated toxicity, poor transfection, systemic clearance and bio-distribution, degradation in circulation, immune response, and endosomal sequestration. Even though, remarkable strategies for miRNA delivery are being developed to overcome these obstacles and facilitate miRNA transport, in the future the rational design of safe and efficient new generation carriers would promote clinical translation of miRNAs. Safety of miRNA-based therapeutics is another challenge that would be clarified in the future.

\section{References}

1. Fouad Y, Aanei C (2017) Revisiting the hallmarks of cancer. Am J Cancer Res. 7: 1016-1036

2. Hanahan D, Weinberg RA (2000) The hallmarks of cancer. Cell 100: 57-70.

3. Hanahan D, Weinberg RA (2011) Hallmarks of cancer: The next generation. Cell. 144: 646-674.

4. Sonnenschein C, Soto AM (2013) The aging of the 2000 and 2011 hallmarks of cancer reviews: A critique. J Biosci 38: 651-663

5. Nguyen DX, Bos PD, Massague J (2009) Metastasis: From dissemination to organ-specific colonization. Nature Rev Cancer 9: 274-284.

6. Bartel DP (2004) MicroRNAs: Genomics, biogenesis, mechanism, and function Cell 116: 281-297.

7. Iorio, MV, Croce CM (2012) Causes and consequences of microRNA dysregulation. Cancer J 18: 215-222.

8. Esquela-Kerscher A, Slack FJ (2006) Oncomirs-microRNAs with a role in cancer. Nature Rev Cancer 6: 259-269.

9. Davis-Dusenbery BN, Hata A (2010) Mechanisms of control of microRNA biogenesis. J Biochem 148: 381-392.

10. Berezikov E, Guryev V, Van De Belt J, Wienholds E, Plasterk RH, et al. (2005) Phylogenetic shadowing and computational identification of human microRNA genes. Cell 120: 21-22.

11. Li Z, Rana TM (2014) Therapeutic targeting of microRNAs: Current status and future challenges. Nature Rev Drug Discovery 13: 622-638.

12. Bohnsack MT, Czaplinski K, Gorlich D (2004) Exportin 5 is a RanGTPdependent dsRNA-binding protein that mediates nuclear export of pre-miRNAs. RNA 10: 185-191.

13. Yi R, Qin Y, Macara IG, Cullen BR (2003) Exportin-5 mediates the nuclear export of pre-microRNAs and short hairpin RNAs, Genes Dev 17:3011-1.

14. Li Z, Rana TM (2012) Molecular mechanisms of RNA-triggered gene silencing machineries. Accounts Chem Res 45: 1122-1131.

15. Krol J, Loedige I, Filipowicz W (2010) The widespread regulation of microRNA biogenesis, function and decay. Nature Rev Genet 11: 597-610.

16. Triboulet R, Chang HM, Lapierre RJ, Gregory RI (2009) Post-transcriptional control of DGCR8 expression by the microprocessor. RNA 15: 1005-1011.

17. Gregory RI, Yan KP, Amuthan G, Chendrimada T, Doratotaj B, et al. (2004) 
The microprocessor complex mediates the genesis of microRNAs. Nature 432 235-240.

18. Chendrimada TP, Gregory RI, Kumaraswamy E, Norman J, Cooch N, et al. (2005) TRBP recruits the Dicer complex to Ago2 for micro RNA processing and gene silencing. Nature 436: 740-744.

19. Yu X, Li Z (2016) The role of TARBP2 in the development and progression of cancers. Tumour Biol 37: 57-60

20. Paroo Z, Ye X, Chen S, Liu Q (2009) Phosphorylation of the human microRNAgenerating complex mediates MAPK/Erk signaling. Cell 139: 112-122.

21. Wightman B, Ha I, Ruvkun G (1993) Posttranscriptional regulation of the heterochronic gene lin-14 by lin-4 mediates temporal pattern formation in C. elegans. Cell 75: 855-862.

22. Pillai RS, Bhattacharyya SN, Artus CG, Zoller T, Cougot N, et al. (2005) Inhibition of translational initiation by Let-7 microRNA in human cells. Sci 309: 1573-1576.

23. Eichhorn SW, Guo H, Mc Geary SE, Rodriguez-Mias RA, Shin C, et al. (2014) mRNA destabilization is the dominant effect of mammalian microRNAs by the time substantial repression ensues. Mol Cell 56: 104-115.

24. Stefanie Jonas, Elisa Izaurralde (2015) Towards a molecular understanding of microrna-mediated gene silencing. Nature Rev Genetics 16: 421-433.

25. Chapata C, Jafarnejada SM, Matta-Camachoa E, Heskethc GG, Gelbartd IA, et al. (2017) Cap-binding protein 4EHP effects translation silencing by microRNAs. PNAS 114: 21-27.

26. Cora' D, Re A, Caselle M, Bussolino F (2017) MicroRNA-mediated regulatory circuits: Outlook and perspectives. Phys Biol 14: 045001.

27. Bosia C, Sgrò F, Conti L, Baldassi C, Brusa D, et al. (2017) RNAs competing for microRNAs mutually influence their fluctuations in a highly non-linear microRNA-dependent manner in single cells. Genome Bio 18: 37.

28. Park JH, Shin S, Shin C (2017) Non-canonical targets destabilize microRNAs in human Argonautes. Nucleic Acids Res 45: 1569-1583.

29. Calin GA, Dumitru CD, Shimizu M, Bichi R, Zupo S, et al. (2022) Frequent deletions and down-regulation of micro-RNA genes miR15 and miR16 at $13 q 14$ in chronic lymphocytic leukemia. Proc Natl Acad Sci USA 99: 15524-15529.

30. Price C, Chen J (2014) MicroRNAs in cancer biology and therapy: Current status and perspectives. Genes Diseases 1: 53-63.

31. Zhao M, Kim P, Mitra R, Zhao J, Zhao Z (2015) TSGene 2.0: An updated literature-based knowledgebase for tumor suppressor genes. Nucleic Acids Res 44: D1023-D1031.

32. Inamura K (2017) Major tumor suppressor and oncogenic non-coding RNAs: Clinical relevance in lung cancer. Cells 6: 12 .

33. Peng Y, Croce CM (2016) The role of microRNAs in human cancer. Signal Transduction and Targeted Therapy 1: 15004.

34. Iorio MV, Croce CM (2012) Causes and consequences of microRNA dysregulation. Cancer J 18: 215-222.

35. Lin S, Gregory RI (2015) MicroRNA biogenesis pathways in cancer. Nat Rev Cancer 15: 321-333.

36. Calin GA, Croce CM (2006) MicroRNAs and chromosomal abnormalities in cancer cells. Oncogene 25: 6202-6210.

37. Tagawa H, Seto M (2005) A microRNA cluster as a target of genomic amplification in malignant lymphoma. Leukemia 19: 2013-2016.

38. Hayashita Y, Osada H, Tatematsu Y, Yamada H, Yanagisawa K, et al. (2005) A polycistronic microRNA cluster, miR-17-92, is overexpressed in human lung cancers and enhances cell proliferation. Cancer Res 65: 9628-9632.

39. Mavrakis KJ, Wolfe AL, Oricchio E, Palomero T, De Keersmaecker K, et al. (2010) Genome-wide RNA-mediated interference screen identifies miR-19 targets in Notch-induced T-cell acute lymphoblastic leukaemia. Nat Cell Biol 12: $372-379$

40. Zhang L, Huang J, Yang N, Greshock J, Megraw MS, et al. (2006) MicroRNAs exhibit high frequency genomic alterations in human cancer. Proc Natl Acad Sci USA 103: 9136-9141.

41. Calin GA, Sevignani C, Dumitru CD, Hyslop T, Noch E, et al. (2004) Human
microRNA genes are frequently located at fragile sites and genomic regions involved in cancers. Proc Natl Acad Sci USA 101: 2999-3004.

42. Wang B, Hsu SH, Wang X, Kutay H, Bid HK, et al. (2014) Reciprocal regulation of microRNA-122 and c-Myc in hepatocellular cancer: Role of E2F1 and transcription factor dimerization partner 2. Hepatology 59: 555-566.

43. O'Donnell KA, Wentzel EA, Zeller KI, Dang CV, Mendell JT (2005) c-Mycregulated microRNAs modulate E2F1 expression. Nature 435: 839-843.

44. Chang TC, Yu D, Lee YS, Wentzel EA, Arking DE, et al. (2008) Widespread microRNA repression by Myc contributes to tumorigenesis. Nat Genet 40: 43 50 .

45. He L, He X, Lim LP, De Stanchina E, Xuan Z, et al. (2007) A microRNA component of the p53 tumor suppressor network. Nature 447: 1130-1134.

46. Hermeking $\mathrm{H}$ (2010) The miR-34 family in cancer and apoptosis. Cell Death Differ 17: 193-199.

47. Raver-Shapira N, Marciano E, Meiri E, Spector Y, Rosenfeld N, et al. (2007) Transcriptional activation of miR-34a contributes to p53-mediated apoptosis. Mol Cell 26: 731-743.

48. Chang TC, Wentzel EA, Kent OA, Ramachandran K, Mullendore M, et al. (2007) Transactivation of miR-34a by p53 broadly influences gene expression and promotes apoptosis. Mol Cell 26: 745-752.

49. Yamakuchi M, Lotterman CD, Bao C, Hruban RH, Karim B, et al. (2010) p53induced microRNA-107 inhibits HIF-1 and tumor angiogenesis. Proc Natl Acad Sci USA 107: 6334-6339.

50. Xiao J, Lin H, Luo X, Luo X, Wang Z (2011) miR-605 joins p53 network to form a p53: miR-605: Mdm2 positive feedback loop in response to stress. EMBO J 30: 524-532.

51. Zhang Y, Liao JM, Zeng SX, Lu H (2011) p53 downregulates Down syndromeassociated DYRK1A through miR-1246. EMBO Rep 12: 811-817.

52. Suzuki H, Maruyama R, Yamamoto E, Kai M (2013) Epigenetic alteration and microRNA dysregulation in cancer. Front Genet 4: 258

53. Fazi F, Racanicchi S, Zardo G, Starnes LM, Mancini M, et al. (2007) Epigenetic silencing of the myelopoiesis regulator microRNA-223 by the AML1/ETO oncoprotein. Cancer Cell 12: 457-466.

54. Lujambio A, Calin GA, Villanueva A, Ropero S, Sanchez-Cespedes M, et al (2008) A microRNA DNA methylation signature for human cancer metastasis. Proc Natl Acad Sci USA 105: 13556-13561.

55. HataA, Kashima R (2016) Dysregulation of microRNA biogenesis machinery in cancer. Crit Rev Biochem Mol Biol 51: 121-134.

56. Gurtner A, Falcone E, Garibaldi F, Piaggio G (2016) Dysregulation of microRNA biogenesis in cancer: The impact of mutant p53 on Drosha complex activity. $J$ Exp Clinical Cancer Res 35: 45.

57. Romero-Cordoba SL, Salido-Guadarrama I, Rodriguez-Dorantes M, HidalgoMiranda A (2014) miRNA biogenesis: Biological impact in the development of cancer. Cancer Biol Ther 15: 1444-1455.

58. Melo SA, Moutinho C, Ropero S, Calin GA, Rossi S, et al. (2010) A genetic defect in exportin-5 traps precursor miRNAs in the nucleus of cancer cells. Cancer Cell 18: 303-315.

59. Melo SA, Ropero S, Moutinho C, Aaltonen LA, Yamamoto H, et al. (2009) A TARBP2 mutation in human cancer impairs microRNA processing and DICER1 function. Nat Genet 41: 365-370.

60. Wegert J, Ishaque N, Vardapour R, Geörg C, Gu Z, et al. (2015) Mutations in the SIX1/2 pathway and the DROSHA/DGCR8 miRNA microprocessor complex underlie high-risk blastemal type Wilms tumors. Cancer Cell 27: 298-311.

61. Walz AL, Ooms A, Gadd S, Gerhard DS, Smith MA, et al. (2015) Recurrent DGCR8, DROSHA, and SIX homeodomain mutations in favorable histology Wilms tumors. Cancer Cell 27: 286-297.

62. Lee RJ, Albanese C, Fu M, D'Amico M, Lin B, et al. (2000) Cyclin D1 is required for transformation by activated $\mathrm{Neu}$ and is induced through an E2F-dependent signaling pathway. Mol Cell Biol 20: 672-683.

63. Sylvestre Y, De Guire V, Querido E, Mukhopadhyay UK, Bourdeau V, et al. (2007) An E2F/miR-20 an autoregulatory feedback loop. J Biol Chem 282 2135-2143.

64. Lu Y, Thomson JM, Wong HY, Hammond SM, Hogan BL (2007) Transgenic 
overexpression of the microRNA miR17-92 cluster promotes proliferation and inhibits differentiation of lung epithelial progenitor cells. Dev Biol 310: 442-453.

65. Woods K, Thomson JM, Hammond SM (2007) Direct regulation of an oncogenic micro-RNA cluster by E2F transcription factors. J Biol Chem 282: 2130-2134.

66. Gillies JK, Lorimer IA (2007) Regulation of p27Kip1 by miRNA 221/222 in glioblastoma. Cell Cycle 6: 2005-2009.

67. Galardi S, Mercatelli N, Giorda E, Massalini S, Frajese GV, et al. (2007) miR-221 and miR-222 expression affects the proliferation potential of human prostate carcinoma cell lines by targeting p27Kip1. J Biol Chem 282: 2371623724

68. Visone R, Russo L, Pallante P, De Martino I, Ferraro A, et al. (2007) MicroRNAs (miR)-221 and miR-222, both overexpressed in human thyroid papillary carcinomas, regulate p27Kip1 protein levels and cell cycle. Endocr Relat Cancer 14: 791-798.

69. Lal A, Kim HH, Abdelmohsen K, Kuwano Y, Pullmann Jr R, et al. (2008) p16 (INK4a) translation suppressed by miR-24. PLoS One 3: e1864.

70. Dolezalova D, Mraz M, Barta T, Plevova K, Vinarsky V, et al. (2012) MicroRNAs regulate $\mathrm{p} 21$ (Waf1/Cip1) protein expression and the DNA damage response in human embryonic stem cells. Stem Cells 30: 1362-1372.

71. Du B, Wang Z, Zhang X, Feng S, Wang G, et al. (2014) MicroRNA-545 suppresses cell proliferation by targeting cyclin D1 and CDK4 in lung cancer cells. PLoS One 9: e88022.

72. Peng Y, Dai Y, Hitchcock C, Yang X, Kassis ES, et al. (2013) Insulin growth factor signaling is regulated by microRNA-486, an under expressed microRNA in lung cancer. Proc Natl Acad Sci USA 110: 15043-15048.

73. Lima RT, Busacca S, Almeida GM, Gaudino G, Fennell DA, et al. (2011) MicroRNA regulation of core apoptosis pathways in cancer. Eur $\mathrm{J}$ Cancer 47: 163-174.

74. Li C, Hashimi SM, Good DA, Cao S, Duan W, et al. (2012) Apoptosis and microRNA aberrations in cancer. Clin Exp Pharmacol Physiol 39: 739-746.

75. Pileczki V, Cojocneanu-Petric R, Maralani M, Neagoe lb, Sandulescu R (2016) MicroRNAs as regulators of apoptosis mechanisms in cancer. Clujul Med 89: 50-55.

76. Fornari F, Gramantieri L, Giovannini C, Veronese A, Ferracin M, et al. (2009) MiR-122/cyclin G1 interaction modulates p53 activity and affects doxorubicin sensitivity of human hepatocarcinoma cells. Cancer Res 69: 5761-5767.

77. Burns DM, D'Ambrogio A, Nottrott S, Richter JD (2011) CPEB and two poly (A) polymerases control miR-122 stability and p53 mRNA translation. Nature 473: 105-108.

78. Yan HL, Xue G, Mei Q, Wang YZ, Ding FX, et al. (2009) Repression of the miR17-92 cluster by p53 has an important function in hypoxia-induced apoptosis. EMBO J 28: 2719-2732.

79. Zhang S, Liu Z (2016) Effect of miRNAs in lung cancer suppression and oncogenesis. Open Life Sci 11: 441-446.

80. Sacconi A, Biagioni F, Canu V, Mori F, Di Benedetto A, et al. (2012) miR-204 targets Bcl-2 expression and enhances responsiveness of gastric cancer. Cell Death Dis 3: e423.

81. Zhang H, Li Y, Huang Q, Ren $\mathrm{X}$, Hu H, et al. (2011) MiR-148a promotes apoptosis by targeting $\mathrm{Bcl}-2$ in colorectal cancer. Cell Death Differ 18: 17021710.

82. Nie J, Liu L, Zheng W, Chen L, Wu X, et al. (2012) microRNA-365, downregulated in colon cancer, inhibits cell cycle progression and promotes apoptosis of colon cancer cells by probably targeting cyclin D1 and Bcl-2. Carcinogenesis 33: 220-225.

83. Denoyelle C, Lambert B, Meryet-Figuière M, Vigneron N, Brotin E, et al. (2014) miR-491-5p-induced apoptosis in ovarian carcinoma depends on the direct inhibition of both BCL-XL and EGFR leading to BIM activation. Cell Death Dis 5: e1445.

84. Zhang CZ, Zhang JX, Zhang AL, Shi ZD, Han L, et al. (2010) MiR-221 and miR222 target PUMA to induce cell survival in glioblastoma. Mol Cancer 9: 229.

85. Mo JS, Alam KJ, Kang IH, Park WC, Seo GS, et al. (2015) MicroRNA 196B regulates FAS-mediated apoptosis in colorectal cancer cells. Oncotarget 6 :2843-2855.
86. Grisard E, Nicoloso MS (2017) Following MicroRNAs through the cance metastatic cascade. Int Rev Cell Mol Biol 333: 173-228.

87. Ma L, Teruya-Feldstein J, Weinberg RA (2007) Tumor invasion and metastasis initiated by microRNA-10b in breast cancer. Nature 449: 682-688.

88. Spahn M, Kneitz S, Scholz CJ, Stenger N, Rüdiger T, et al. (2009) Expression of microRNA-221 is progressively reduced in aggressive prostate cancer and metastasis and predicts clinical recurrence. Int J Cancer 127: 394-403.

89. Saini S, Majid S, Shahryari V, Arora S, Yamamura S, et al. (2012) miRNA-708 control of CD44(+) prostate cancer-initiating cells. Cancer Res 72: 3618-3630.

90. Liu C, Kelnar K, Liu B, Liu C, Kelnar K, et al. (2011) The microRNA miR-34a inhibits prostate cancer stem cells and metastasis by directly repressing CD44. Nat Med 17: 211-215.

91. Huang Q, Gumireddy K, Schrier M, Le Sage C, Nagel R, et al. (2008) The microRNAs miR-373 and miR-520c promote tumor invasion and metastasis. Nat. Cell Biol 10: 202-210.

92. Seven M, Karatas OF, Duz MB, Ozen M (2014) The role of miRNAs in cancer: from pathogenesis to therapeutic implications. Future Oncol 10: 1027-1048.

93. Tiwari A, Mukherjee B, Dixit M (2017) MicroRNA key to angiogenesis regulation: miRNA biology and therapy. Curr Cancer Drug Targets 18: 266-277.

94. Camps C, Buffa FM, Colella S, Moore J, Sotiriou C, et al. (2008) hsa-miR-210 is induced by hypoxia and is an independent prognostic factor in breast cancer Clin Cancer Res 14: 1340-1348.

95. Fasanaro P, D'Alessandra $Y$, Di Stefano V, Melchionna R, Romani S, et al. (2008) MicroRNA-210 modulates endothelial cell response to hypoxia and inhibits the receptor tyrosine kinase ligand Ephrin-A3. J Biol Chem 283: 1587815883.

96. Lou YL, Guo F, Liu FL, Gao FL, Zhang PQ, et al. (2012) MiR-210 activates notch signaling pathway in angiogenesis induced by cerebral ischemia. Mol Cell Biochem 370: 45-51.

97. Liu F, Lou YL, Wu J, Ruan QF, Xie A, et al. (2012) Upregulation of microRNA-210 regulates renal angiogenesis mediated by activation of VEGF signaling pathway under ischemia/perfusion injury in vivo and in vitro. Kidney Blood Press Res 35: 182-191.

98. Ghosh G, Subramanian IV, Adhikari N, Zhang X, Joshi HP, et al. (2010) Hypoxiainduced microRNA-424 expression in human endothelial cells regulates HIFalpha isoforms and promotes angiogenesis. J Clin Invest 120: 4141-4154.

99. Lei Z, Li B, Yang Z, Fang H, Zhang GM, et al. (2009) Regulation of HIF-1alpha and VEGF by miR-20b tunes tumor cells to adapt to the alteration of oxygen concentration. PLoS One 4: e7629.

100. Cha ST, Chen PS, Johansson G, Chu CY, Wang MY, et al. (2010) MicroRNA $519 \mathrm{c}$ suppresses hypoxia-inducible factor-1alpha expression and tumor angiogenesis. Cancer Res 70: 2675-2685.

101. Shah MY, Ferrajoli A, Soodc AK, Lopez-Berestein G, Calin GA (2016) MicroRNA therapeutics in cancer- an emerging concept. EBioMedicine 12 34-42.

102. Ji W, Sun B, Su C (2017) Targeting microRNAs in cancer gene therapy. Genes 8: 21.

103. Joana FL, Laura C, Ceu F, Carla O, Nuno FA (2018) Anti-miRNA oligonucleotides: A comprehensive guide for design, RNA Biology 15: 338-352.

104. Boutla A, Delidakis C, Tabler M (2003) Developmental defects by antisensemediated inactivation of micro-RNAs 2 and 13 in Drosophila and the identification of putative targets. Nucleic Acid Res 31: 4973-4980.

105. Obad S, Dos Santos CO, Petri A, Heidenblad M, Broom O, et al. (2011) Silencing of microRNA families by seed-targeting tiny LNAs. Nat Genet 43:371-378.

106. Lennox KA, Behlke MA (2011) Chemical modification and design of antimiRNA oligonucleotides. Gene Ther 18:1111-1120.

107. Davis S, Lollo B, Freier S, Esau C (2006) Improved targeting of miRNA with antisense oligonucleotides. Nucleic Acids Res 34: 2294-2304.

108. Krützfeldt J, Kuwajima S, Braich R, Rajeev KG, Pena J, et al. (2007) Specificity duplex degradation and subcellular localization of antagomirs. Nucleic Acids Res 35: 2885-2892.

109. Kloosterman WP, Lagendijk AK, Ketting RF, Moulton JD, Plasterk RH (2007) 
Citation: Mekuria AN, Abdi AD, Mishore KM (2018) MicroRNAs as a Potential Target for Cancer Therapy. J Cancer Sci Ther 10: 152-161. doi: 10.4172/1948-5956.1000535

Targeted inhibition of miRNA maturation with morpholinos reveals a role for miR-375 in pancreatic islet development. PLoS Biol 5: e203.

110. Fabani MM, Gait MJ (2008) miR-122 targeting with LNA/20 -O-methyl oligonucleotide mixmers, peptide nucleic acids (PNA), and PNA-peptide conjugates. RNA 14: 336-346.

111. Chan JA, Krichevsky AM, Kosik KS (2005) MicroRNA-21 is an antiapoptotic factor in human glioblastoma cells. Cancer Res 65: 6029-6033.

112. Griveau A, Bejaud J, Anthiya S, Avril S, Autret D, et al. (2013) Silencing of miR-21 by locked nucleic acid-lipid nanocapsule complexes sensitize human glioblastoma cells to radiation-induced cell death. Int J Pharm 454: 765-774.

113. Ebert MS, Neilson JR, Sharp PA (2007) MicroRNA sponges: Competitive inhibitors of small RNAs in mammalian cells. Nat Methods 4: 721-726.

114. Chen L, Zhang K, Shi Z, Zhang A, Jia Z, et al. (2014) A lentivirus-mediated miR-23b sponge diminishes the malignant phenotype of glioma cells in vitro and in vivo. Oncol Rep 31: 1573-1580.

115. Di Giorgio A, Tran TP, Duca M (2016) Small-molecule approaches toward the targeting of oncogenic miRNAs: Roadmap for the discovery of RNA modulators. Future Med Chem 8: 803-816.

116. Gumireddy K, Young DD, Xiong X, Hogenesch JB, Huang Q, et al. (2008) Small-molecule inhibitors of miR-21 function. Angew Chem 47: 7482-7484.

117. Young DD, Connelly CM, Grohmann C, Deiters A (2010) Small molecule modifiers of microRNA miR-122 function for the treatment of hepatitis $C$ virus infection and hepatocellular carcinoma. J Am Chem Soc 132: 7976-7981.

118. Bader AG, Brown D, Winkler M (2010) The promise of microRNA replacement therapy. Cancer Res 70: 7027-7030.

119. Bader AG (2012) miR-34: A microRNA replacement therapy is headed to the clinic. Front Genet 3: 120.

120. Li J, Wan X, Qiang W, Li T, Huang W, et al. (2015) MiR-29a suppresses prostate cell proliferation and induces apoptosis via KDM5B protein regulation Int J Clin Exp Med 8: 5329-5339.

121. Calin GA, Cimmino A, Fabbri M, Ferracin M, Wojcik SE, et al. (2008) MiR-15a and miR-16-1 cluster functions in human leukemia 105: 5166-5171.

122. Gong JN, Yu J, Lin HS, Zhang XH, Yin XL, et al. (2014) The role, mechanism and potentially therapeutic application of microRNA-29 family in acute myeloid leukemia. Cell Death Differ 21: 100-112.

123. Xiong Y, Fang JH, Yun JP, Yang J, Zhang Y, et al. (2010) Effects of microRNA-29 on apoptosis, tumorigenicity, and prognosis of hepatocellular carcinoma. Hepatol 51: 836-845.

124. Esquela-Kerscher A, Trang P, Wiggins JF, Patrawala L, Cheng A, et al. (2008) The let-7microRNA reduces tumor growth in mouse models of lung cancer. Cell Cycle 7: 759-764

125. Trang P, Medina PP, Wiggins JF, Ruffino L, Kelnar K, et al. (2010) Regression of murine lung tumors by the let-7 microRNA. Oncogene 29: 1580-1587.

126. Trang P, Wiggins JF, Daige CL, Cho C, Omotola M, et al. (2011) Systemic delivery of tumor suppressor microRNA mimics using a neutral lipid emulsion inhibits lung tumors in mice. Mol Ther 19: 1116-1122.

127. Zheng Y, Yin L, Chen H, Yang S, Pan C, et al. (2012) miR-376a suppresses proliferation and induces apoptosis in hepatocellular carcinoma. FEBS Lett 586: 2396-2403.

128. Liu C, Kelnar K, Liu B, Chen X, Calhoun-Davis T, et al. (2011) The microRNA miR-34a inhibits prostate cancer stem cells and metastasis by directly repressing CD44. Nat Med 17: 211-215.

129. Michelfelder S, Trepel M (2009) Adeno-associated viral vectors and their redirection to cell-type specific receptors. Adv Genet 67: 29-60.

130. Blankinship MJ, Gregorevic P, Allen JM, Harper SQ, Harper H, et al. (2004) Efficient transduction of skeletal muscle using vectors based on adenoassociated virus serotype 6. Mol Ther 10: 671-678.

131. Kota J, Chivukula RR, O'Donnell KA, Wentzel EA, Montgomery CL, et al. (2009) Therapeutic microRNA delivery suppresses tumorigenesis in a murine liver cancer model. Cell 137: 1005-1017.

132. Chen L, Zheng J, Zhang Y, Yang L, Wang J, et al. (2011) Tumor-specific expression of microRNA-26a suppresses human hepatocellular carcinoma growth via cyclin-dependent and -independent pathways. Mol Ther 19: 15211528

133. Naso MF, Tomkowicz B, Perry WL, Strohl WR (2017) Adeno-Associated Virus (AAV) as a vector for gene therapy. BioDrugs 31: 317-334 